\title{
ARBITRAGEM: INSTRUMENTO EFETIVO DE ACESSO À JUSTIÇA*
}

\section{ARBITRATION AS AN EFFECTIVE INSTRUMENT TO ACCESS JUSTICE}

\author{
Rozane da Rosa Cachapuz \\ Elaine C. Gomes Condado***
}

\begin{abstract}
Resumo: $\mathrm{O}$ estudo sobre a arbitragem ganhou atualidade no Brasil com a Lei $\mathrm{n}^{\mathbf{a}}$ 9.307/96. Para tanto, é imprescindível a abordagem do acesso à justiça como garantia constitucional a todo cidadão, como um instrumento à disposição de todos. $\mathrm{O}$ acesso à justiça assegura a efetividade da aplicação do direito, constituindo-se a arbitragem num instrumento efetivo desse acesso. A arbitragem objetiva em servir como mecanismo opcional e hábil, voltado à resolução dos conflitos. Apresenta-se como forma heterocompositiva de resolução de controvérsias de direitos patrimoniais disponíveis e detentora de força executória.
\end{abstract}

Palavras-chave: Princípios. Arbitragem. Acesso à justiça. Constitucionalidade. Justiça Coexistencial. Árbitros. Celeridade. Economia. Imparcialidade. Tecnicidade. Confidencialidade. Sentença arbitral detentora de força executória. Relevância do instituto na atualidade.

Abstract: Arbitration studies have won status in Brazil with Law number 9.307/96. It considers that it is necessary to approach access to justice as a constitutional guarantee to every citizen as an instrument available to all. Access to justice assures the effectiveness of law application, and arbitration constitutes an effective instrument for such access. It aims to work as a capable and optional mechanism for the solution of conflicts. It is a heterocompositive form to solve existing patrimonial law controversies with execution power.

Keywords: Arbitration. Access to justice . Constitutionality. Co-existential justice. Arbitrators. Celerity. Economy. Impartiality. Tenacity. Confidentiality. Arbitral sentence with execution power. Relevance of the institute at present.

Este artigo é resultado de Dissertação apresentada no Mestrado em Direito Negocial da Universidade Estadual de Londrina (UEL) no ano de 2007.

Doutora em Direitos das Relações pela PUC-SP. Professora da Universidade Estadual de Londrina.

Mestre em Direito Negocial pela Universidade Estadual de Londrina. Especialista em Direito Empresarial pela Universidade Estadual de Londrina. Professora e advogada em Londrina. 


\section{INTRODUÇÃO}

Desde o final do século XX, a arbitragem revela-se uma constante preocupação da comunidade jurídica com o direito do cidadão de buscar, no âmbito do Poder Judiciário, a solução para a entrega rápida da prestação jurisdicional, hoje erigida, em nosso ordenamento legal, como direito substancial de caráter individual ou coletivo. Essa é a razão pela qual a doutrina contemporânea tem se preocupado, com forte intensidade, em abordar o tema e em difundir as idéias construídas a respeito, no sentido de sensibilizar o Estado para o cumprimento dessa suprema garantia do direito do cidadão.

Geralmente faz-se uma associação direta entre o acesso à justiça e o acesso aos tribunais. Porém, nos dias de hoje, essa visão não mais satisfaz. Esse acesso formal, por meio do processo, perante os órgãos do Poder Judiciário, onde se identifica o problema e se diz o direito como forma de realizar justiça, não é, na atualidade, o melhor modelo e, muito menos, aquele que proporciona um maior acesso à justiça. Hoje é preciso uma acepção mais ampla para proporcionar aos cidadãos um acesso, não apenas aos tribunais e ao resultado da prestação jurisdicional, desenvolvido pelo Estado, mas a uma ordem jurídica justa.

Ao longo das últimas três décadas, tem-se multiplicado fóruns de discussão sobre gestão dos conflitos, tendo como resultado a institucionalização de meios alternativos de solução de conflitos aos tribunais judiciais. Muito se tem falado sobre métodos alternativos para a solução de conflitos, na língua inglesa - Alternative Dispute Resolution - ADR. Surgidos no meio dos negócios - políticos e comerciais - os meios alternativos de solução de controvérsias se mostraram um modo eficaz de finalizar lides de variada complexidade através dos tempos.

Essa nova realidade levou a profundas alterações, tanto de ordem política, social, econômica e cultural, quanto na forma que o homem se relaciona com o mundo, especialmente no que diz respeito aos negócios e às formas de solução das controvérsias. Com a expansão do comércio, a tendência de abertura dos mercados e a internacionalização das economias, a arbitragem reafirmou-se não somente entre particulares, mas também entre Estados, como instituto essencial ao desenvolvimento do comércio internacional. As mudanças nas relações internacionais provocaram transformações no ordenamento jurídico dos Estados e a opção pela formação de grandes blocos econômicos e comerciais têm gerado mudanças radicais, não apenas nos sistemas produtivos dos países, mas também numa reavaliação dos modelos de solução de controvérsias existentes, que imprimam maior agilidade e velocidade. 
$\mathrm{Na}$ medida em que essas transformações se expandem, maiores se tornam os vínculos entre eles, evidenciando-se mais a constatação dessa interdependência, pois nenhum país é auto-suficiente o bastante na produção de bens e serviços, já que cada um deles é dotado de forma diferente, no que diz respeito a recursos naturais, clima, tecnologia e assim por diante.

A adoção de métodos alternativos como forma de resolução de conflitos está de acordo com os princípios e modelo atual de Estado, em que o cidadão é o centro dos interesses da sociedade e seu voluntarismo passa a ser elemento político dentro de políticas públicas de soluções de conflitos.

Ao utilizar-se da via alternativa, o cidadão obterá a solução de seu conflito, porém, se não ocorrer o cumprimento do acordo deverá socorrer-se do poder estatal para que este faça uso de sua autoridade e monopólio da coação, por meio do Judiciário e da execução forçada.

Assim, retirar do Estado a possibilidade de dizer o direito, não retira dele seu poder ou fere sua soberania, muito pelo contrário, a confirma, pois é por autorização dele que estes mecanismos se tornam possíveis e é por intermédio de sua autoridade que se aceita tornar possível seu uso e se confere força às suas resoluções, traço característico da soberania, que é o uso da força.

De sorte que, a Lei de Arbitragem significa uma verdadeira revolução na cultura jurídica brasileira, à medida que coloca lado a lado a jurisdição estatal com a privada, à escolha do jurisdicionado. $\mathrm{O}$ direito processual civil precisa retomar a sua dimensão social, adequando-se historicamente às realidades e necessidades dos novos tempos, a começar pelo rompimento do mito do monopólio estatal da jurisdição, exorcizando o terror da imposição da cláusula arbitral em todo e qualquer contrato, sem que isso importe em enfraquecimento do Judiciário ou na inafastabilidade do controle jurisdicional.

\section{A RELEVÂNCIA DO INSTITUTO DA ARBITRAGEM}

A importância da arbitragem cada vez mais vem sendo defendida, uma vez que possui um caráter amplo, abrangendo relações entre os particulares, especialmente no âmbito comercial e internacional. A arbitragem conduz os envolvidos a uma solução rápida de seus problemas, e mais, promove o exercício eficaz da cidadania quando os leva a assumir a responsabilidade pela satisfação de sua necessidade na situação posta, e, conseqüentemente, o leva a participar na administração da justiça. $O$ indivíduo exercita o seu direito, a liberdade, maior expressão da democracia.

A arbitragem, como instituição, segundo o professor Paulo de Tarso Santos, começa a funcionar em harmonia com o Poder Judiciário que, como um dos 
Poderes Constitucionais, tem amplas e importantes funções que vão além das controvérsias de direito privado. (SANTOS, 2001, p. 79).

A mobilidade do capital cresceu, graças à agilidade dos meios de comunicação, que a cada dia estão mais velozes. Como poderia então este capital ficar atrelado ao Poder Judiciário lento e ineficaz? Nos Estados Unidos, por exemplo, grande parte das controvérsias são solucionadas fora do Judiciário, ficando este na retaguarda, caso os jurisdicionados dele necessitem. É seu dever ficar permanentemente atento ao desenvolvimento da sociedade, ouvindo e respondendo ao seu clamor, dando soluções satisfatórias e, por que não dizer, produzindo consideráveis precedentes e tendências a serem seguidas pela sociedade brasileira.

Está no próprio indivíduo o melhor caminho para obter justiça e, ao tomar para si, essa solução de forma pacífica, passa a exercer não apenas os propalados direitos de cidadão, mas assume também a ordenação da vida social, além de auxiliar na escrita dos desígnios da sociedade. O objetivo da arbitragem é evitar que o Judiciário emperre, colaborando com o seu desafogamento e dando uma maior agilidade na solução das controvérsias. Somente quando a solução torna-se impossível é que se recorre ao sistema tradicional da prestação jurisdicional.

Constata-se, pois, a importância não só da sumarização das formas e das tutelas de urgência, em suas mais variadas formas, o complexo contexto sóciojurídico do acesso à justiça, como também dos métodos ou técnicas diferenciadas ou alternativas de solução de conflitos, como elementos indispensáveis desse movimento, cuja filosofia reflete exatamente, nos dizeres de Mauro Capelletti (1994, p. 96), “[...] a tentativa de adicionar uma dimensão social ao Estado de Direito, de passar do Rechtsstaat ao socializer Rechtsstaat, consoante proclamam as mais avançadas Constituições européias (francesa, alemã e espanhola) [...]”.

Em 1995, antes, portanto, da Lei nª 9.307/96, Cezar Fiúza (1995) sustentava que:

A arbitragem no Brasil não é problema legal: o que mais pesa é a questão cultural. [...] por razões talvez históricas, a cultura brasileira transformou o Estado em pai e mãe de todos. Dele dependemos para tudo. Ele é o grande culpado por todos nossos males e, também, o único benfeitor. Sintetiza o Estado Brasileiro as figuras do bandido, do mocinho, do bode expiatório e do salvador da pátria. Por via de conseqüência, como é do Estado a tarefa de resolver todos nossos problemas, compete a ele, e só a ele, a tarefa de julgar nossos litígios. Realmente, não fosse o aspecto cultural, seria difícil compreender o desuso do instituto (da arbitragem) em nosso país. (p. 217-218). 
Para Carlos Alberto Carmona (2004), a arbitragem pode ser conceituada como:

Meio alternativo de solução de controvérsias através da intervenção de uma ou mais pessoas que recebem seus poderes de uma convenção privada, decidindo com base nela, sem intervenção estatal, sendo a decisão destinada a assumir a mesma eficácia da sentença judicial - é colocada à disposição de quem quer que seja - para solução de conflitos relativos a direitos patrimoniais acerca dos quais os litigantes possam dispor. (p. 51).

Nesse sentido, é o entendimento de Rozane da Rosa Cachapuz (2000), que conceitua o instituto da arbitragem:

Como sendo um foro privilegiado e propício para a composição amigável ou para a convergência dos esforços dos litigantes no sentido de alcançarem rapidamente, sem descurar dos valores maiores que são a segurança e a justiça da decisão, a solução final da lide, tendo em vista que, quase sempre, ambos têm interesses na resolução do conflito, que, não raras vezes, envolve quantias vultosas de dinheiro, com inúmeros efeitos diretos e reflexos. (p. 23).

Assim, apesar da distribuição da justiça ser da competência do Judiciário, por meio dos juízes e tribunais, visando à restauração coercitiva de um direito ameaçado ou violado, a lei abre uma exceção e permite que as lides inerentes a direitos patrimoniais sejam solucionados via arbitral. A esse respeito, Nelson Godoy Bassil Dower (1996), comentando o instituto da arbitragem, afirma que:

Contudo, a lei abre uma exceção a essa exclusividade: permite que a solução de lides e conflitos de interesses, desde que relativos a direitos patrimoniais, se façam pela forma privada, ou seja, pela autocomposição, através do chamado juízo arbitral, tal como está previsto no artigo 1.072, do Código de Processo Civil. (p. 40).

Nesse sentido, Joel Dias Figueira Júnior (1999, p. 14) ressalta a necessidade de reavaliar e reorganizar a jurisdição pública e enfatiza a necessidade de facultar às partes "a opção pela jurisdição privada ou paraestatal para solução de conflitos que envolvam direitos patrimoniais disponíveis, segundo se verifica no novo regime arbitral instituído pela Lei $n^{-3}$ 9.307/96”. E, certa relação de causa e efeito, entre o Judiciário, em crise, e a arbitragem, não é realidade só no Brasil.

A arbitragem não veio a substituir o procedimento judicial, tampouco ela ressurge como solução milagrosa, visto que não consegue abarcar a maioria dos litígios, pela limitação do objeto que pode ser arbitrado e pelo custo relativamente alto que é despendido pela instauração de um tribunal arbitral.

Por meio da arbitragem, foi concedido às próprias partes um modo de 
solucionar seus litígios, resultantes de determinadas relações jurídicas de direito privado, a um tribunal arbitral, composto por um arbitro único ou uma maioria deles, designados, em principio, pelas partes ou por uma entidade por elas indicada. Mediante a instituição do tribunal arbitral, exclui-se a competência dos juízes estatais para julgar a mesma lide. (RECHSTEINER; FRANCO; WALD, 2005, p. 16)

Cumpre ainda dizer que, a arbitragem é um meio de resolução de conflitos, mais simples e objetiva, e, os julgadores, além de imparciais, são técnicos especializados na área científica sobre a qual recai objeto litigioso” (CACHAPUZ, 2000, p. 22). A opção pelo juízo arbitral é facultativa no tocante ao órgão arbitral, pois se nomeia um único árbitro ou optam para que um grupo de árbitros decida sobre a questão. Os poderes conferidos pelos árbitros são derivados do acordo entre as partes e em virtude de lei.

A arbitragem constitui-se assim, em mecanismo mais flexível, podendo disciplinar os novos litígios, satisfazendo uma exigência da vida moderna, por ser baseada no princípio da autonomia da vontade. Exemplo dessa adaptação é o Centro de Arbitragem e Mediação por parte da Organização Mundial de Propriedade Intelectual (World Intellectual Property Organization), que segundo Hiram Chodosh (1999) foi criado "em resposta à incapacidade dos sistemas jurídicos nacionais de lidar com a complexidade técnica e com as múltiplas jurisdições de tais disputas". O centro tem por objetivo assegurar o ritmo das mudanças nos mercados nacionais e nos globais emergentes, o que resulta em pressões cada vez maiores sobre os grandes interesses comerciais, para resolver as disputas rapidamente, a baixo custo e de forma amistosa, construtiva e criativa, para maximizar os interesses em longo prazo e para resolver as relações comerciais existentes.

Em que pese a arbitragem prestar-se adequadamente à solução de conflitos de natureza diversa, adquire foro preferencial e finalidade específica em questões decorrentes de relações comerciais e, em particular, as internacionais, em que há necessidade de conhecimentos específicos, tanto de direito internacional e comercial, como de costumes e praxes do comércio, portanto, sendo visíveis as suas vantagens.

A arbitragem, sem deixar o devido processo legal, é mais simples e objetiva, e os julgadores, além de imparciais, são técnicos especializados na área científica sobre a questão em que consiste o litígio e, em regra, com profundo conhecimento científico e respeitabilidade, atributos estes, que presentes, conferem às partes um julgamento seguro e rápido, sobretudo comparandoos com a jurisdição pública. 
É propriamente na relação tempo versus rapidez que o jurisdicionado defronta-se com o maior obstáculo à consecução de suas pretensões. Joel Dias Figueira Júnior (1999, p. 139) assevera que "seja esse talvez o principal ponto de estrangulamento do Poder Judiciário brasileiro e, também, nos do chamado países do primeiro mundo". Complementa ainda que "diante da carência de estrutura material, instrumental, tecnológica e de pessoal, na qual se encontra mergulhado o nosso Poder Judiciário, inegável que se verifica um comprometimento parcial do direito ao amplo acesso aos tribunais e à ordem jurídica justa". (FIGUEIRA JÚNIOR, 1999, p. 140).

Apropriado, pois, os dizeres de Célio Borja (1995) quanto à relevância da arbitragem:

Se, porventura, o instituto do juízo arbitral ao se qualificar pela simplicidade, segurança e celeridade para resolver os litígios oriundos dos contratos civis e mercantis celebrados pelos agentes econômicos, parece-me difícil prever como o sistema judiciário estatal se desincumbirá do acréscimo significativo da demanda por seus serviços. (p. 102).

Sem sombra de dúvida, a arbitragem, de acordo com o que dispõe a Lei $\mathrm{n}^{\underline{a}}$ 9.307, de 23 de setembro de 1996, preenche o vazio cultural jurídico até então existente em nosso sistema processual. Dada a sua importância no cenário institucional processual, há de ser cultuada com intensa profundidade, a fim de se firmar uma cultura que leve os variados setores da sociedade a aceitá-la e nela confiar, para enfrentar os litígios sem a interferência do Judiciário. A possibilidade de sua utilização na solução das controvérsias, em larga escala, não pode ser descartada, mormente no Brasil, em que se reclama tanto da morosidade da justiça. Daí a inafastável conclusão de que nenhuma decisão judicial, por mais acertada que seja, sob o aspecto técnico-jurídico, é justa, se proferida depois de alguns anos de tormentosa espera, repleta de angústias e incertezas ${ }^{1}$.

${ }^{1} \mathrm{O}$ mais expressivo exemplo está na questão dos precatórios, alimentares ou não. Esgotada a instância de conhecimento da matéria, ou seja, após tornada irrecorrível a decisão de última instância, não raro a cargo do STF ou STJ, inicia-se a longa espera pelo cumprimento da condenação imposta à Fazenda Pública. O Estado de São Paulo, por exemplo, deve, em precatórios, mais de dez bilhões de reais $(\mathrm{R} \$ 10.000 .000 .000,00)$. Isso corresponde a $1 / 6$ de sua receita bruta anual. Receber depois de dez ou doze anos o valor da condenação determinada judicialmente, após um processo que tramitou por cinco ou mais anos, corresponderá isso a uma "decisão justa"? 
No Brasil,

Em dez anos, realizou-se uma evolução que, em outros países, levou quase um século. Tudo mudou no campo da arbitragem. As estatísticas são eloqüentes. De um número insignificante de processos arbitrais, em 1996, ano em que foi promulgada a nova lei, passou-se para cerca de 4.000 arbitragens realizadas anualmente, das quais cerca de noventa por cento no campo trabalhista e do direito do consumidor, e as demais em questões comerciais, internacionais e domésticas. (MARTINS, 2006).

Efetivamente, enquanto o processo judicial é uma espécie de "guerra", que afasta as partes, a arbitragem tenta manter as relações entre as mesmas de modo que possam continuar a atuar em conjunto, nos contratos de longo prazo, quer como fornecedores e clientes, quer como sócios.

O sucesso da arbitragem no Brasil, repita-se, deve em grande parte à posição dos juristas. O Supremo Tribunal Federal reconheceu a constitucionalidade da lei. Por sua vez, o Superior Tribunal de Justiça facilitou a homologação das decisões arbitrais estrangeiras, aplicando, de imediato, a nova lei, admitindo a convenção de arbitragem tácita, definindo mais adequadamente a ordem pública e consagrando a arbitrabilidade dos conflitos, nos quais uma das partes é sociedade de economia mista.

Por outro lado, os juízes de primeiras instâncias e os tribunais estaduais passaram a apreciar as decisões arbitrais com menor formalismo, só decretando a sua nulidade em raros casos de violação do direito da defesa ou de suspeição de árbitros.

Já no plano internacional, a inclusão da convenção de arbitragem nos contratos facilita as relações comerciais, atrai os investimentos e dá maiores garantias aos contratantes, permitindo inclusive a redução dos custos de transação.

O século XXI se caracteriza pela velocidade. Em virtude das novas tecnologias e da globalização, a solução dos litígios não pode eternizar-se. É preciso, todavia, que as decisões dos conflitos não sejam tão-somente rápidas, sendo imprescindível que também sejam eficientes e justas. Num mundo conturbado, com tribunais sobrecarregados, a arbitragem é a melhor alternativa para determinados casos, em que se podem obter soluções eficientes, justas e éticas. Eis o mérito da Lei n⿳亠丷厂 9.307/96. (MARTINS, 2006). 


\section{A PRÁTICA ARBITRAL}

A arbitragem passa por um momento de consolidação no Brasil, com seu peso se concentrando cada vez mais nas áreas cível e comercial, além da trabalhista. Várias câmaras arbitrais estão se reestruturando para concentrar mais os processos, pois o número dos que são realizados no país ainda é muito pequeno se comparado com o elevado volume de procedimentos que existem na Justiça Estatal.

Indo além dos números, o Jornal Valor Econômico informa que as empresas brasileiras estão optando pela utilização de cláusulas de arbitragem em seus negócios e estima que, no campo internacional, 99\% dos contratos elejam o mecanismo. Revela, também, que a difusão dos métodos alternativos de solução de controvérsias como a arbitragem, a mediação e a negociação está criando um novo campo de atuação para profissionais do Direito. (MACIEL, 2004).

Apesar do crescimento do uso da arbitragem no Brasil [...] na Câmara BrasilCanadá, uma das maiores, por exemplo, tem hoje apenas 17 conflitos em andamento. Já a Câmara do Novo Mercado, criada há dois anos, ainda não tem nenhum. No caso das disputas societárias, o número de procedimentos é ainda menor. Daí o ineditismo da discussão sobre seu sigilo. (GOULART, 2005).

Nessa seara, o árbitro e vice-presidente da Câmara da Bovespa, Paulo Cezar Aragão, diz que é difícil fixar uma regra e que a decisão deve ser da companhia. O também árbitro da Bovespa, Calixto Salomão Filho, defende até mesmo que a Comissão de Valores Mobiliários (CVM) exija a divulgação da instalação de qualquer procedimento arbitral no Novo Mercado - não necessariamente com a abertura de todas as informações do processo. Para o diretor da CVM, Marcos Barbosa Pinto, os conflitos que são resolvidos por meio de arbitragem devem ser regidos pela Instrução CVM n⿳a 358 , que define os casos em que as empresas precisam divulgar fatos relevantes (GOULART, 2005).

De outra sorte, a seccional paulista da Ordem dos Advogados do Brasil $(\mathrm{OAB} / \mathrm{SP})$ está empenhada em investir na popularização da arbitragem e da mediação entre os advogados (NOVA..., 2007). Essa decisão, da diretoria da $\mathrm{OAB}$, será implantada pelo novo presidente da Comissão de Mediação e Arbitragem do Estado de São Paulo, o advogado Arnoldo Wald Filho, que já está com muitos projetos para difundir mais o uso das práticas alternativas de solução de conflitos. Entre os planos, há a possibilidade de firmar um convênio com a Federação das Indústrias do Estado de São Paulo (Fiesp) para 
recrutar estagiários de Direito interessados em atuar na Câmara de Arbitragem e Mediação do órgão. Ele também pretende convencer as faculdades de Direito a oferecer mais matérias sobre o tema com o intuito de preparar os estudantes para essa nova realidade.

Wald Filho, que é árbitro da Câmara da Fundação Getúlio Vargas e sócio do Wald e Associados Advogados, um dos escritórios brasileiros que mais atuam no campo internacional e interno da arbitragem, acredita que poderá transformar a cidade de São Paulo em centro de referência de arbitragem da América Latina. Isso por meio de todo esse trabalho que será desenvolvido pela $\mathrm{OAB}$ paulista. Ressalta também a importância do Brasil no cenário mundial da arbitragem. Segundo suas pesquisas, na Corte Internacional de Arbitragem da Câmara de Comércio Internacional (CCI) de Paris, o Brasil, em dez anos, passou de um dos últimos lugares do ranking, considerando-se o número de partes brasileiras nas arbitragens, para o primeiro lugar na América Latina, superando o México. Com relação ao mundo, já é o quarto país, logo após os Estados Unidos, a França e a Alemanha, à frente de países como a Inglaterra e a Itália (NOVA..., 2007).

Enfatiza ainda Wald Filho que, a circunstância de um mundo pluripolarizado impõe a São Paulo, ao lado dos centros tradicionais de arbitragem, como Paris, Londres e Nova York, um protagonismo fundamental na solução de litígios locais e internacionais - um posicionamento que só destaca a responsabilidade da OAB paulista na consecução de seus objetivos (NOVA..., 2007).

Já internamente no país, a previsão é de que são feitas mais de quatro mil arbitragens por ano. Esse número é baseado em estimativas, pois os procedimentos muitas vezes não são contabilizados por serem confidenciais. A maioria é feita no Estado de São Paulo. Os litígios resolvidos por arbitragem são, na maior parte, comerciais e trabalhistas (AGUIAR, 2007).

Entre 1997 e 2004, segundo levantamento da OAB e do Conselho Nacional de Mediação e Arbitragem (CONIMA), o número de câmaras arbitrais, muitas constituídas por associações comerciais, federações de indústrias e outras entidades de classes, pulou de 17 para 79. Atualmente, já há mais de 100 câmaras em todo o País. Das 15 câmaras mais procuradas pela iniciativa privada, 4 estão sediadas em São Paulo e 2 no Rio de Janeiro. A OAB-SP tem projetos para investir na popularização da arbitragem e da mediação entre os advogados no Brasil. Hoje, já há mais de 22 mil processos acumulados no País (AGUIAR, 2007).

Nos últimos anos, a demanda por essa forma extrajurisdicional de resolução 
de litígios, em disputas civis e comerciais, aumentou quase 60\%. Ao todo, entre 1.999 e 2.005 foram resolvidos por esse método 13.652 casos, a maioria nos setores de petróleo e gás, energia elétrica, farmacêutico, automobilístico e de seguros. Recentemente, as áreas de construção civil, locação de imóveis e empresas de distribuição passaram a recorrer à arbitragem. Para efeitos comparativos, a American Arbitration Association, uma entidade criada há mais de 50 anos e que atua em 41 países, só em 2.002 administrou mais de 200 mil casos, dos quais 3 mil envolviam disputas comerciais com valor superior a US\$ 250 mil (DEZ..., 2006).

De outro lado, de acordo com o Conselho Arbitral do Estado de São Paulo (Caesp), o sistema, como alternativa para a solução de conflitos vem ganhando espaço, de igual maneira, na área trabalhista, mas em 2005, o balanço demonstrou uma tendência inovadora, em especial a arbitragem trabalhista em 22 estados brasileiros por intermédio de Câmaras itinerantes (FERREIRA NETTO, 2005).

Segundo dados da Câmara de Arbitragem, o crescimento de processos na área comercial de 2005 em relação a 2004 foi de 44,79\%, e na área cível foi de $12,8 \%$ (DUVA, 2006). São percentuais que podem demonstrar o cenário atual na área arbitral do País, afinal, são as duas áreas mais procuradas em todas as entidades de arbitragem no Brasil, em especial a arbitragem trabalhista em 22 estados brasileiros por intermédio de Câmaras itinerantes. $\mathrm{O}$ crescimento nessas áreas acontece porque o sistema no Brasil ainda está em desmistificação entre os advogados para chegar aos empresários. Nota-se que o empresariado, executivos em especial, começa a perceber a importância do sistema. É um jogo de paciência. Devagar e sempre.

Os principais casos solucionados em 2005 na Câmara de Arbitragem Empresarial de São Paulo (SP Arbitral) também foram nas áreas que houve um maior crescimento no ano. Houve um aumento de 35 a 40\%, que tem parceria da Secretaria de Justiça e da Defesa da Cidadania, Junta Comercial do Estado de São Paulo, Federação do Comércio do Estado de São Paulo, Federação dos Contabilistas do Estado de São Paulo, Ordem dos Advogados do Brasil - Seccional de São Paulo, Associação dos Peritos Judiciais do Estado de São Paulo, Câmara Ítalo-Brasileira de Comércio e Indústria de São Paulo e Instituto Brasileiro de Avaliações e Perícias de Engenharia. Ademais, os conflitos solucionados pelos institutos de arbitragem são resolvidos em apenas 180 dias e a decisão do árbitro vale como sentença judicial, não cabendo recurso. A arbitragem, como é segura, ágil e eficiente, é uma das alternativas mais procuradas por empresas e pessoas físicas para contornar a lentidão do Poder Judiciário (DUVA, 2006). 
Também com o intuito de estimular o uso de formas alternativas para a solução de conflitos, o Conselho Nacional de Justiça (CNJ) firmou um acordo, em março deste ano com a Fiesp, para que as empresas possam usar mais a mediação.

O Ministério da Justiça (DUVA, 2006) não arrisca metas quantitativas, mas insiste no efeito cumulativo com o primeiro pacote de medidas que, em 2006, permitiu uma ligeira redução da pendência 0,4\%, equivalente a 6.675 processos. "O ponto essencial é que não são medidas avulsas, mas a continuação de um esforço de descongestionamento que se iniciou em 2005”, salientou ao JN o ministro da tutela, Alberto Costa. Entre as medidas aprovadas contamse várias que visam incentivar o recurso aos meios de resolução alternativa de litígios, como as seguintes:

a) Alargamento do Sistema de Mediação Familiar a todo o território nacional, até ao final de 2008;

b) Alargamento do Sistema de Mediação Laboral a todo o território nacional, até ao final de 2008;

c) Criação de 8 novos julgados de paz até 2008;

d) Criação de um centro de arbitragem para dirimir litígios em matéria de propriedade industrial, cujos atos necessários para a concretização devem ser aprovados até ao final de 2007;

e) Criação de centros de arbitragem em matéria de ação executiva;

f) Incentivo à utilização dos meios de resolução alternativa de litígios por meio do regime das custas judiciais.

Essas medidas visam promover o acesso ao direito e alargar a oferta do Sistema de Justiça a novos meios de resolução de litígios, permitindo resolver conflitos de forma mais rápida e barata para as partes do que por meio dos tribunais judiciais. Estes meios de resolução alternativa de litígios constituem um meio eficaz para tentar solucionar conflitos antes de promover uma ação judicial. As estruturas de resolução alternativa de litígios que poderão ser utilizadas para este efeito - julgados de paz, centros de arbitragem, sistemas de mediação, entre outros - serão obrigatoriamente definidas por portaria do Ministro da Justiça.

$\mathrm{Na}$ mesma seara, a Comissão de Constituição e Justiça e de Cidadania (CCJ) aprovou o Projeto de Lei 913/07, que modifica o Código de Processo Civil (Lei 5869/73) para incluir os honorários do árbitro na lista dos títulos executivos extrajudiciais. O projeto, do deputado Carlos Alberto Leréia (PSDBGO), foi aprovado em caráter conclusivo e segue para o Senado. O projeto 
será analisado apenas pela Comissão de Constituição e Justiça e Cidadania (Proposta PL - 913/2007) ${ }^{2}$.

Os honorários do árbitro já são previstos pela Lei da Arbitragem (9307/ 96), inclusive como título executivo extrajudicial, instrumento que contém a obrigação incondicionada de pagamento. No entanto, o artigo 585 do Código de Processo Civil, que trata dos títulos executivos extrajudiciais, não faz referência a esses honorários. O objetivo do projeto é incluir expressamente no código os honorários do árbitro, quando fixados pelas partes no compromisso arbitral.

O relator do projeto, deputado Zenaldo Coutinho (PSDB-PA), apresentou parecer favorável: "O projeto contribui para a unificação da lista de títulos executivos extrajudiciais, trazida pelo Código de Processo Civil, e dá a devida importância ao instituto da arbitragem, sem dúvida de grande valia para o desafogamento do Poder Judiciário brasileiro” (CÂMARA..., 2007).

Percebe-se, com isso, que tanto a arbitragem e as outras formas alternativas extrajudiciais de solução de conflitos se mostram vantajosas em relação aos processos judiciais, e esta perspectiva já foi assimilada culturalmente pelos empresários norte-americanos. Já no Brasil, segundo afirma a advogada Selma Lemes "ao analisar um negócio, o investidor avaliará a possibilidade de economizar na hora de resolver divergências. Isso porque, com a arbitragem, não terá de arcar com o gasto de tempo com o Judiciário" (apud FERNANDES, 2006, p. 69). Aduz ainda que, “a arbitragem só não é mais usada por desconhecimento. Mas quem usou uma vez, certamente não volta mais ao Poder Judiciário quando tiver problemas. (apud VAZ, Revista Exame PME, Julho/Agosto de 2006, p. 76).

A necessidade de investimentos privados para complementar a atuação do Estado, em contratos de longo prazo - que, pela sua natureza, pressupõem o uso tanto da arbitragem quanto da mediação - é outro fator fundamental para o investimento nessa modalidade de justiça privada. É por isso que as leis recentes a respeito da concessão e das Parcerias Público-Privadas contêm uma previsão de arbitragem, mediante a inclusão de cláusula compromissória.

"Com efeito, a jurisprudência que vem se consolidando na área admiravelmente, explicitando e ratificando os conceitos e princípios da lei de arbitragem, além de exarar, como no caso a baixo citado, verdadeira lição pedagógica” (LEMES, 2006).

${ }^{2}$ Cf. Agência Câmara - Notícias da OAB em http://www.oablondrina.org.br. Acesso em 16 out. 2007. 
Neste sentido é de relevo salientar a decisão advinda do Tribunal de Justiça do Paraná (Agravo de Instrumento 174.874-9/02 - 2ํㅡara da Fazenda Pública do Foro Central da Comarca da Região Metropolitana de Curitiba), proferida em abril de 2005 sobre questão envolvendo sociedade de economia mista distribuidora de energia elétrica que, ao firmar contratos de compra e venda de energia elétrica de empresa privada, estabeleceu a arbitragem como forma de solução de conflitos deles advindos. Porém, surgidas controvérsias referentes aos pagamentos correspondentes, foram instauradas arbitragens. Mas se insurgiu a sociedade de economia mista quanto à discussão da controvérsia em sede arbitral, alegando que a matéria em tela seria indisponível.

Essa questão, no direito da arbitragem, é conceituada como arbitrabilidade objetiva, pois se refere à disponibilidade de direitos patrimoniais (artigo 1aㅡ, in fine, da Lei $\mathrm{n}^{\mathrm{a}}$ 9.307/96). A sociedade de economia mista, quando atua na compra e venda de energia elétrica, está praticando atividade puramente comercial, desprovida de qualquer reflexo no direito administrativo.

Foi neste sentido que o juiz Fernando César Zeni afirmou que energia elétrica é mercadoria e, portanto, direito disponível (Lei $\mathrm{n}^{\mathrm{a}}$ 10.488/04, artigo 4aㅡ, $\S 5^{\underline{a}}$ e $\left.7^{\underline{a}}\right)$. Destarte, a questão é econômica e não pública, sendo perfeitamente válida a cláusula compromissória. Ademais, a sociedade de economia mista sujeita-se às regras de mercado e à legislação contratual civil. Saliente-se que a sociedade de economia mista não poderia, sob o manto da indisponibilidade do interesse público (por integrar a administração pública indireta), eximir-se do que legalmente firmara (pacta sunt servanda). Não há possibilidade sequer de anular administrativamente contratos que regulam relações da administração em caráter privado ("não pode a administração anular atos realizados sob o império do direito privado” - TAPR , Ap. C. 247.646-0, 7. CC, j. 11.02.04).

Note-se, ademais, que a confirmação jurisprudencial em reconhecer definitivamente a capacidade da administração pública direta e indireta em firmar a convenção de arbitragem em contratos com particulares, alinha-se com os contratos de concessão de serviços públicos da época imperial; no precedente denominado "Caso Lage”; no caso de saneamento básico julgado pelo Tribunal de Justiça do Distrito Federal em 1999; no famoso "Caso Lloyd Brasileiro v. Ivarans Rederi”, sendo o extinto Lloyd uma empresa de economia mista; a "Compagás”, no Estado do Paraná etc.

Mas a lição pedagógica que fica deste acórdão, que já se inscreve como um leading case para os casos em que as sociedades de economia mista e a administração pública firmam contratos com cláusula de arbitragem, é que 
"não se pode permitir que por vias oblíquas a Lei de Arbitragem seja reduzida à inutilidade”. E mais, sua função pedagógica vale como uma advertência aos que pretendem obstaculizar o regular e irreversível papel que a arbitragem desempenha como forma de acesso à Justiça, no despertar do século XXI.

É sabido que países desenvolvidos tratam a arbitragem de forma inerente aos seus sistemas econômicos e jurídicos. Nos Estados Unidos, à título ilustrativo, há uma expressão que se imortalizou “[...] não é mais o meio alternativo de solução de conflitos e sim, o meio propício à solução de conflitos [...].” (JUDICIAL REFORM ROUNDTABLE II, 1996, apud BUSHATSKY, 2005).

Ora, se etimologicamente a palavra processo significa ir para frente, a reformulação, pois, faz-se indispensável e urgente e, parafraseando Benjamin Cardozo, em sua evocação a Roscoe Pound, "o direito deve ser estável, mas não pode permanecer estático, o jurista, como o viajante, deve estar pronto para o amanhã” (ALMEIDA FILHO, 2002). Esta é a missão que nos cabe: criar um novo processo e com ele uma nova justiça, para responder aos desafios de um novo tempo.

\section{CONCLUSÃO}

A arbitragem consagra o cidadão na administração da justiça e o acesso à justiça é o meio de se promover o Estado de Direito. Este é o momento de abrir os horizontes e trilhar os caminhos alternativos de solução de conflitos que, com certeza, conduzirá ao canal que dá acesso à efetiva realização da justiça.

É entendimento corrente que a demora na entrega definitiva da prestação jurisdicional pelo Poder Judiciário vem servindo de forte estímulo à adoção da arbitragem. Entretanto, é preciso a comunidade jurídica dar um passo a mais, no sentido de entender a essência da Lei de Arbitragem, sua principal finalidade, que é a efetividade da justiça, a melhor forma de utilizá-la, corrigindo-se alguns pontos no meio do caminho, se necessário for, a fim de que, verdadeiramente, seja efetivado o acesso à justiça, direito e esperança de todo homem.

Em conseqüência, a mudança cultural é o caminho para harmonizar, pelo diálogo, o processo arbitral e a jurisdição estatal. Não se trata de substituir uma cultura por outra, mas sim de reconhecer a existência das duas opções: o Poder Judiciário e o juízo arbitral, à escolha do jurisdicionado, os quais já coexistem numa dualidade cultural harmônica. 
Dessa forma, a arbitragem soluciona alguns dos problemas sérios pelos quais atravessa o Poder Judiciário, visto que poderão ser objeto de arbitragem os conflitos que versarem sobre direitos patrimoniais disponíveis, como dispõe o artigo 1aㅡ, da Lei 9.307/96. Ela, pois, não alcança todos os conflitos de um modo geral e, além disso, só é utilizada por pessoas que estejam adaptadas e informadas a respeito do instituto.

Há de se ter em consideração que os direitos e garantias fundamentais vistos na era contemporânea não podem receber interpretação idêntica a que se fazia em épocas passadas. Vivencia-se, na atualidade, uma transformação do modelo até então adotado para o Estado, buscando-se novas estruturas para o seu funcionamento.

A Lei $\mathrm{n}^{-}$9.307/96, ao regular o instituto jurídico da arbitragem, introduziu pois, no ordenamento nacional, novos princípios e conceitos que ainda demandarão algum tempo para serem devidamente assimilados pela comunidade jurídica. Assim, não constituiu surpresa que, de chofre, a lei de arbitragem estreou com alguns dispositivos questionados no Supremo Tribunal Federal - STF que, dissecando-os, selou de modo irrefutável e vanguardeiro a constitucionalidade da lei. Entre outras matérias o julgado referendou o efeito vinculante da convenção de arbitragem (cláusula compromissória e compromisso) e a eficácia da cláusula arbitral cheia.

Assim, a arbitragem na forma instituída no Brasil atende, conseqüentemente, aos propósitos fundamentais veiculados na Carta Magna e se aproxima dos anseios do povo de conviver com uma justiça rápida, segura, desburocratizada e de fácil acesso. Há a necessidade, porém, que o Estado estimule a criação de órgãos arbitrais, facilitando o seu funcionamento e criando condições materiais para que cumpram a missão a que estão destinados.

Sem sombra de dúvida que, a arbitragem tem um grande papel a desempenhar na sociedade, especialmente no tocante à viabilização do efetivo acesso à justiça. Indiscutível sua utilização na distribuição da justiça, razão pela qual, cada vez mais, deva ser valorizada e escolhida pelo cidadão, como um instrumento extrajudicial de solução de controvérsias e como alternativa para o enfrentamento dos litígios no âmbito privado, sem a ingerência do Judiciário. Atualmente, em termos de Direito, a opção do juízo arbitral é o que existe de mais moderno nas soluções dadas a grandes conflitos na área econômica.

Noutra seara, é ponto pacífico que a arbitragem, amparada pela nova e moderna roupagem da Lei $\mathrm{n}^{-}$9.307/96 e dos artigos 851, 852 e 853 do Código Civil brasileiro, referentes ao compromisso, fez evoluir o processo decisório, 
subtraindo considerável demanda da Justiça comum, porquanto reduzirá o seu volume de trabalho em questões complexas e que, via de regra, demandavam elevados custos aos litigantes, seja de ordem econômica, seja temporal.

Afora isto, a morosidade, o formalismo excessivo, o ritualismo e a perplexidade do juiz diante de situações não rotineiras, são traços marcantes e comuns a qualquer processo entranhado na Justiça brasileira, principalmente a dos grandes pólos urbanos, acentuando-se mais quando se exigem conhecimentos mais técnicos do magistrado.

De sorte que, empresas de todos os portes estão gradualmente exigindo em seus contratos a inclusão da cláusula que alude à arbitragem como o melhor modo de solução de conflitos. É fato pois, que a arbitragem será a justiça do futuro. As câmaras de arbitragem registram aumento na procura de seus serviços e reconhecem na área bom potencial de crescimento.

Donde se vê que, a arbitragem está inserida no desenvolvimento dos povos, convivendo até hoje com o sistema institucional para dirimir litígios. O filósofo Aristóteles preleciona que o homem é um animal político, visto que o homem precisa viver em sociedade, uma vez que ele não consegue colocar em prática tudo que necessita. Em assim sendo, o Estado tem a função de organizar o coletivo. E ao aplicar a lei, o Estado expatriou a arbitragem como uma alternativa para resolver litígios, pela rapidez com que a tecnologia e o conhecimento transformam a realidade da vida, exigindo dos indivíduos da sociedade, profundas alterações diárias nos comportamentos e costumes, frente às descobertas e mudanças constantes do convívio social, sobretudo em vista de sua finalidade pacificadora.

Somente assim, com uma visão ampla e voltada para o futuro, é que poderão emergir deste novo contexto experiências e resultados absolutamente positivos, ao encontro dos interesses dos consumidores do Direito, além de fazer renascer a crença no Judiciário e no ideal de Justiça, o que se coaduna perfeitamente com a prestação de tutela por intermédio da justiça privada - a arbitragem.

Como forma alternativa de solução de conflitos, a institucionalização da arbitragem, com toda certeza, desafogará o Judiciário, proporcionando maior tranqüilidade aos juízes estatais, permitindo que se voltem à solução das demandas de maior complexidade, proferindo decisões mais qualificadas. Com isso, haverá maior satisfação pelos jurisdicionados, vez que a realização dos seus direitos se dará de forma mais célere e justa. Refletindo-se também, o esmero científico que se buscou dar ao instituto no Brasil, dentro do figurino moderno e afinado com os modelos mais atualizados da técnica contemporânea. 
Posta assim a questão, conclui-se que a arbitragem é uma conquista para o Direito brasileiro, representando a mais ampla possibilidade de acesso à ordem jurídica justa, permitindo uma aplicação igualitária do Direito, tornando o instituto mais um aliado na concreção da Justiça, guiando a sociedade em direção ao seu objetivo maior, que é a paz social, sob a máxima de que "uma grande Nação é aquela que possui leis justas e uma justiça rápida e não onerosa, conforme consta na Bíblia Sagrada, em sua nova tradução na linguagem de hoje, no Livro de Deuteronômio, em seu Capítulo 4, Versículo 8.

\begin{tabular}{|c|c|c|}
\hline & ARBITRAGEM & \begin{tabular}{|l} 
JUSTIÇA ESTATAL \\
\end{tabular} \\
\hline $\begin{array}{l}\text { TEMPO MÉDIO } \\
\text { DE UM PROCESSO }\end{array}$ & Mês (es) & Anos \\
\hline $\begin{array}{l}\text { CUSTAS DO } \\
\text { PROCEDIMENTO }\end{array}$ & $\begin{array}{l}\text { Muito inferiores às custas } \\
\text { públicas, portanto, bem } \\
\text { suportadas pelas partes }\end{array}$ & $\begin{array}{l}\text { Custas processuais }+ \\
\text { honorários advocatícios }+ \\
\text { ônus da sucumbência }\end{array}$ \\
\hline $\begin{array}{l}\text { CUSTAS COM } \\
\text { ADVOGADOS }\end{array}$ & Não há obrigatoriedade & Obrigatório \\
\hline $\begin{array}{l}\text { POSSIBILIDADE DE } \\
\text { NEGOCIAÇÃO }\end{array}$ & Ampla / Total & Restrita \\
\hline SIGILO DO PROCESSO & Sigiloso & Público \\
\hline RECURSO & Não há & $\begin{array}{l}\text { Vários (recurso ordinário, } \\
\text { especial, extraordinário, } \\
\text { embargos, etc.) }\end{array}$ \\
\hline JURISDIÇÃO & Não há & $\begin{array}{l}\text { Depende do valor e da } \\
\text { matéria da ação, bem } \\
\text { como da localidade }\end{array}$ \\
\hline $\begin{array}{l}\text { EFICÁCIA DA } \\
\text { SENTENÇA }\end{array}$ & $\begin{array}{l}\text { A sentença arbitral é } \\
\text { proferida em uma única } \\
\text { instância, constituindo, } \\
\text { imediatamente, título } \\
\text { executivo judicial }\end{array}$ & $\begin{array}{l}\text { A sentença judicial } \\
\text { somente se constitui em } \\
\text { título executivo após o } \\
\text { julgamento do último } \\
\text { recurso ajuizado pela } \\
\text { parte interessada }\end{array}$ \\
\hline
\end{tabular}

Quadro comparativo com o Poder Judiciário. 


\section{REFERÊNCIAS}

AGUIAR, Adriana. Arbitragem e mediação já têm 22 mil processos acumulados. 2007. Disponível em: 〈http://www.taab.com.br/noticia2.asp?cod=74>. Acesso em: 30 out. 2007.

ALMEIDA FILHO, José Carlos de Araújo. Arbitragem - um instituto legal, porém deturpado. Revista Iberoamericana de Arbitraje y Mediación, junio 2002. Disponível em: <http://www.servilex.com.pe/arbitraje/colaboraciones/ arbitragem.html $>$. Acesso em: 30 jan. 2007.

BARRAL, Weber. A arbitragem e seus mitos. Florianópolis: OAB/SC, 2000.

BORJA, Célio. O juízo arbitral. Revista de Informação Legislativa, Brasília, n. 125, p. 97-102, 1995.

BUSHATSKY, Daniel. Ampliação da arbitragem: Câmaras devem julgar litígios entre estado e setor privado. Consultor Jurídico, São Paulo, 20 mar. 2005. Disponível em: <http://www.conjur.com.br/static/text/33653,1〉. Acesso em: CACHAPUZ, Rozane da Rosa. Arbitragem: alguns aspectos do processo e do procedimento na Lei 9.307/96, São Paulo: Editora de Direito, 2000.

CÂMARA aprova inclusão de honorários de árbitro em código. Disponível em: $<$ http://www.caesp.org.br/modules.php? name $=$ News $\&$ file $=$ article\&sid $=634>$. Acesso em: 16 out. 2007.

CAPPELLETTI, Mauro. Os métodos alternativos de solução dos conflitos no quadro do movimento universal de acesso à Justiça. Revista de Processo, São Paulo, v. 19, n. 74, p. 82-97, ab./jun. 1994.

CAPPELLETTI, Mauro; GARTH, Bryant. Acesso a justiça. Trad. Ellen Gracie Northfleet. Porto Alegre: Fabris, 1998.

CARMONA, Carlos Alberto. Arbitragem e Processo: um comentário à Lei 9.307/96. 2 ed. rev., atual e ampl. São Paulo: Atlas, 2004.

CHODOSH, Hiram E. A mediação jurídica e a cultura legal. Questões de Democracia, Washington, DC, v. 4, n. 3, dez. 1999. Disponível em: <http://usinfo.state.gov/journals/itdhr/1299/ijdp/chodosh.htm>. Acesso em: 19 jan. 2007.

CONCEIÇÃO, Joaquim Tavares. Justiça conciliatória ou coexistencial: um exemplo Sergipiano. In: BARRAL, Welber; ANDRADE, Henri Glay (Org.). $O$ Judiciário em Sergipe: análise crítica. Aracaju: OAB, 2000. 
CRETELLA NETO, José. Comentários à lei de arbitragem brasileira. Rio de Janeiro: Forense, 2004.

DELGADO, José Augusto. A arbitragem: direito processual da cidadania. Revista Jurídica, Porto Alegre, ano 49, n. 282, p. 5-18, abr. 2001.

DEZ anos de arbitragem. O Estado de São Paulo, São Paulo, 25 abr. 2006. Disponível em: <http://www.estado.com.br/editorias/2006/04/25/edi102311.xml>. Acesso em: 30 jan. 2007.

DOWER, Nelson Godoy Bassil. Direito processual civil. 2. ed. São Paulo: Nelpa, 1996. v. 1.

DUVA, Izabel. Arbitragem se consolida nas áreas cível e comercial. 2006. Disponível em: <http://www.taab.com.br/noticia2.asp?cod=22>. Acesso em: 31 jan. 2007.

FERNANDES, Simone. A solução fora da corte. Revista Amanhã, São Paulo, ano 20, n. 219, p. 69, abr. 2006. Disponível em: <http://amanha.terra.com.br/ edicoes/219/especial.asp>. Acesso em: 16 out. 2007.

FERREIRA NETTO, Cássio Telles. Arbitragem: uma solução jurídica. 2005. Disponível em: <http://caesp.locaweb.com.br/modules.php?name= Conteudo\&pa=showpage\&pid=96>. Acesso em: 30 jan. 2007.

FIGUEIRA JÚNIOR, Joel Dias. Arbitragem, jurisdição e execução: análise crítica da Lei 9.307, de 23.09.1996. 2. ed. São Paulo: Ed. Revista dos Tribunais, 1999. p. 102-110.

FIUZA, Cézar. Teoria geral da arbitragem. Belo Horizonte: Ed. Del Rey, 1995. GOULART, Josette. Companhias abertas precisam quebrar sigilo das arbitragens. 2005. Disponível em: <http://www.camarb.com.br/informativos/ detalhes.aspx?informativono=51>. Acesso em: 30 out. 2007.

LEMES, Selma Ferreira. Lição pedagógica: a Lei de Arbitragem não pode ser reduzida à inutilidade. Consultor Jurídico, São Paulo, 5 abr. 2006. Disponível em: <http://www.conjur.com.br/static/text/43305,1>. Acesso em: 30 out. 2007.

MACIEL, Marco. Reformas e governabilidade. Brasília: Senado Federal, 2004.

MARTINS, Ives Gandra da Silva. Dez anos da leide arbitragem . Jus Navigandi, Teresina, ano 10, n. 1186, 30 set. 2006. Disponível em: <http://jus2.uol.com.br/ doutrina/texto.asp?id=8992>. Acesso em: 30 out. 2007.

MARTINS, Pedro Antonio Batista. Anotações sobre a arbitragem no Brasil e 
o Projeto de Lei do Senado 78/92. Revista de Processo, São Paulo, n. 77, p. 2564, jan./mar. 1995.

MARTINS, Pedro A. Batista; LEMES, Selma M. Ferreira; CARMONA, Carlos Alberto. Aspectos fundamentais da lei da arbitragem. Rio de Janeiro: Forense, 1999.

MORAIS, José Luis Bolzan. Mediação e arbitragem: alternativas à jurisdição. Porto Alegre: Livraria do Advogado, 1999.

MUJALLI, Walter Brasil. Juízo Arbitral - a nova lei de arbitragem. São Paulo: Led - Editora de Direito, 1997.

MUNIZ, Tânia Lobo. Arbitragem no Brasil e a Lei 9.307/96. Curitiba: Juruá, 2006.

NALINI, José Renato. O juiz e o acesso à justiça. 2. ed. São Paulo: Ed. Revista dos Tribunais, 2000.

NEVES, Flávia Bittar. A visão empresarial da arbitragem: como a administração de conflitos pode melhorar os resultados econômicos e não-econômicos do negócio? Revista Brasileira de Arbitragem, São Paulo, Porto Alegre, ano 2, n. 9, p. 7-29, jan./mar. 2006.

NOVA Ordem: São Paulo será o centro de arbitragem da América Latina. Consultor Jurídico, São Paulo, 15 mar. 2007. Disponível em: 〈http: \\www.conjur.com.br〉. Acesso em: 30 out. 2007.

OLIVEIRA, Régis de. O juiz na sociedade moderna. São Paulo: FTD, 1997.

PINTO, Luiz Roberto Nogueira. Arbitragem: a alternativa premente para descongestionar o Poder Judiciário. São Paulo: Arte \& Ciência, 2002.

RECHSTEINER, Beat Walter; FRANCO, Mariulza; WALD, Arnold. Arbitragem em ritmo de expansão. RT Informa, São Paulo, ano 4, n. 35, jan./ fev. 2005.

SANTOS, Boaventura de Souza. Introdução à sociologia da administração da justiça. In: FARIA, José Eduardo (Org.). Direito e Justiça: a função social do Judiciário. 2. ed. São Paulo: Ática, 1994.

SANTOS, Paulo de Tarso. Arbitragem e Poder Judiciário: mudança cultural. São Paulo: LTr, 2001.

SILVA, Adriana dos Santos. Acesso à justiça e arbitragem: um caminho para a crise do Judiciário. Barueri, SP: Manole, 2005. 
SZKLAROWSKY, Leon Frejda. A justiça na sociedade moderna: a lei de arbitragem no seu décimo aniversário. Consulex. revista jurídica, Brasília, ano 11, n. 240, p. 54-9, jan. 2007.

TEIXEIRA, Sálvio de Figueiredo. A arbitragem no sistema jurídico brasileiro. Revista dos Tribunais, São Paulo, v. 86, n. 735, p. 39-48, jan. 1997.

URY, Willian. Como chegar à paz, resolvendo conflitos em casa, no trabalho e no dia a dia. Rio de Janeiro: Ed. Campus, 2000.

VAZ, Tatiana. Mais rápido e mais barato. 2006. Disponível em: <http:// www.taab.com.br/noticia2.asp?cod=45>. Acesso em: 16 out. 2007.

WALD, Arnaldo. O controle do processo arbitral pela Corte Internacional de Arbitragem da Câmara de Comércio Intrenacional - CCI. Revista do Advogado, São Paulo, ano 26, n. 87, p. 27-35, set. 2006.

WARAT, L. A. O ofício de mediador. Florianópolis: Habistus, 2001.

WATANABE, Kazuo. Acesso à Justiça e sociedade moderna. In: GRINOVER, Ada Pellegrini; DINAMARCO, Cândido Rangel; WATANABE, Kazuo (Coord.). Participação e processo. São Paulo: Ed. Revista dos Tribunais, 1988.

ZANFERDINI, Flávia de Almeida Montigelli. A crise da justiça e do processo e a garantia do prazo razoável. Revista de Processo, São Paulo, ano 28, n. 112, p. 240-67, out./dez. 2003. 